\title{
The patterns of co-occurrence variation are explained by the low dependence of bark beetles (Coleoptera: Scolytinae and Platypodinae) on hosts along altitude gradients
}

Fang Luo ${ }^{2}$, Ling-Zeng Meng ${ }^{1 *} \mathbb{C}$, Jian Wang ${ }^{1}$ and Yan-Hong Liu ${ }^{1}$

\begin{abstract}
Background: Separation of biotic and abiotic impacts on species diversity distribution patterns across a significant climatic gradient is a challenge in the study of diversity maintenance mechanisms. The basic task is to reconcile scaledependent effects of abiotic and biotic processes on species distribution models. Here, we used a hierarchical modeling method to detect the host specificities of bark beetles (Scolytinae and Platypodinae) with their dependent tree communities across a steep climatic gradient, which was embedded within a relatively homogenous spatial niche.

Results: Species turnover of both trees and bark beetles have an opposite pattern along the climatic proxy (represented by the elevation gradients) at the regional scale, but not at local spatial scales. This pattern confirmed the hypothesis wherein emphasis was on influences of macro-climate on local biotic interactions between trees and hosted bark beetle communities, whereas local biotic relations, represented by host specificity dependence, were regionally conserved.

Conclusions: At a confined spatial scale, cross-taxa comparisons of $\beta$-diversity highlighted the importance of simultaneous impacts from both extrinsic factors related to geography and environment, and intrinsic factors related to organism characteristics. The effects of tree abundance and phylogeny diversity on bark beetle diversity were, to a large extent, indirect, operating via changes in bark beetle abundance through spatial and temporal dynamics of resources distribution. Tree host dependence, which was considered and represented by host specificities, plays a minor role on the hosted beetle community in this concealed wood decomposing interacting system.
\end{abstract}

Keywords: Bark beetles, $\beta$-diversity, Spatial scales, Elevation gradient, Host dependence, Plant-insect interactions

\section{Background}

Host specificity between a plant species and its hosted insects along environment gradients is a central issue in diversity maintenance. It is hypothesized that the

*Correspondence: lingzeng_meng@126.com

${ }^{1}$ College of Biological and Agricultural Sciences, Honghe University, Mengzi 661199, Yunnan, China

Full list of author information is available at the end of the article distributional range of a hosted insect is largely determined by the ecological amplitudes of tree species with which they interact, if clear host specificity is observed [1]. That is, scarcity of suitable interacting partners can restrict the potential niche of a hosted insect species [2, 3]. This intrinsically dependent relationship has been used to estimate the global insect diversity through comparisons of trees or tree phylogeny diversity among different regions [4-8], and led to a recent controversy original author(s) and the source, provide a link to the Creative Commons licence, and indicate if changes were made. The images or other third party material in this article are included in the article's Creative Commons licence, unless indicated otherwise in a credit line to the material. If material is not included in the article's Creative Commons licence and your intended use is not permitted by statutory regulation or exceeds the permitted use, you will need to obtain permission directly from the copyright holder. To view a copy of this licence, visit http://creativecommons.org/licenses/by/4.0/. The Creative Commons Public Domain Dedication waiver (http://creativeco mmons.org/publicdomain/zero/1.0/) applies to the data made available in this article, unless otherwise stated in a credit line to the data. 
surrounding global estimates of insect species richness, ranging from 30 million [8] to 4-6 million [6]. However, some existed niche theories $[9,10]$ related to species distribution are based on spatially fine-grained variables associated with local biotic interactions and resourceconsumer dynamics. This means that a potential bias should not be ignored when using the dependent plantspecies diversity index as a surrogate to estimate regionally or globally hosted insect diversity.

The relative importance of biotic factors probably varies between regional and local interacting plants and insects communities because of the entanglements with abiotic factors [11]. Moreover, it depends on the spatial scale in which a compositional change is being considered $[11,12]$. Thus, specific and well-designed sampling experiments are needed to overcome the interactions of different relative importance of biotic and abiotic factors among various spatial scales. A feasible approach to separate these two entangled factors from each other is to detect patterns of relationship between plants and insects beta diversity (hereafter ' $\beta$-diversity') [13], as species cooccurrence probably vary along a specific environmental gradient, at different spatial scales. Basic logic for this approach is that if distribution pattern was determined by insect host specificity, we can expect that plant and insect $\beta$-diversity will be correlated at local (fine), as well as regional (coarse) spatial scales. On the other hand, if patterns were resulted from parallel response to a broad abiotic environmental gradient, we will get a $\beta$-diversity distribution pattern only to be correlated at regional spatial scale [14].

Spatial community structuring in host-specific niches implies the presence of demarcated transition zones where host replacement is most likely to occur (Fig. 1A). These 'host turnover zones' are derived from an integral but unspecified part of the mutualistic niche concept [15, $16]$; it also can be calculated using $\beta$-diversity as aforementioned. Nevertheless, the niche overlap degree and turnover rate between neighboring spatial communities among different biological assemblages might vary (Fig. 1B), because of simultaneous impacts from extrinsic and intrinsic factors, related to geography and environment and to the evolutionary characteristics of organisms, respectively. At a global scale, the $\beta$-diversity of different communities generally decreases along the increasing latitude gradient (from tropical to temperate areas) [17-19]. Cross-taxon comparisons through metaanalyses showed a negative, albeit relatively weak, relationship between $\beta$-diversity and latitude $[20,21]$. What's more interesting is that two $\beta$-diversity components, including nestedness and turnover which were already proposed by Baselga [22], had generally opposing patterns with regard to latitude at a global spatial scale [23]. Some evidences suggested that gradients in $\beta$-diversity occur as a result of latitudinal or elevation gradients and may be caused by a series of combined mechanisms. For
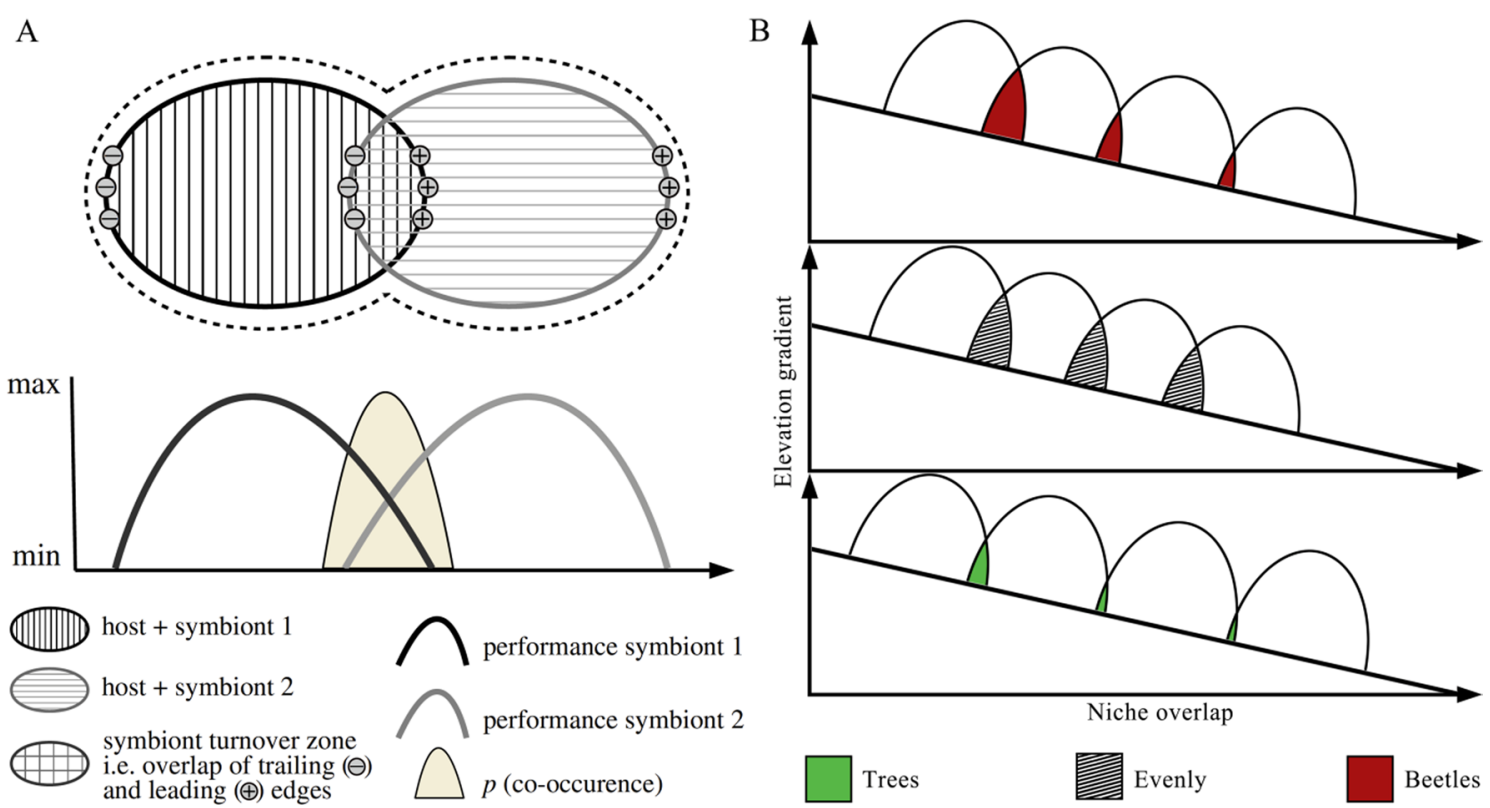

Fig. 1 The space of a host can be subdivided into separate sections, each depending on the presence of particular symbionts (1 and 2) with distinct optimum performance along the respective niche axes (i.e., the elevation niche). Left panel $\mathbf{A}$ is re-sketched from the Fig. 1 of Rolshausen et al. (2020). Right panel B illustrates the niche overlap difference among different taxon across the same environmental elevation gradients 
example, deterministic processes of environmental or habitat filtering at a regional scale [24] and stochastic processes generating ecological drift at a local scale [25] impact spatial community assembly processes differently. Given the complexity of potential interactions among processes that are not mutually exclusive and are mediated by host specificity, it is not surprising that the relative importance of contributing factors and interactive mechanisms in driving patterns of $\beta$-diversity in hosted insects and plants remains largely unresolved.

Recent studies have attempted to overcome the spatial-scale dependence of diversity through a hierarchically nested method [11, 26, 27]. A hierarchical modeling framework [28] of $\beta$-diversity combined with phylogenetic and functional $\beta$-diversity was also proposed and may help to investigate mechanisms of local hosted community assembly. It suggests that if both host plant (henceforth referred as 'host') and insect turnover, which reflect bio-geographical impacts at all scales (from local to regional), occur simultaneously in response to geographic or environmental gradients, we would not expect to find any positive association between insect community composition and plant species/phylogenetic turnover after accounting for the influence of geography or the regional species pool. Therefore, if the observed insect turnover patterns were due to host specificity, a close relationship between insect and host species/phylogenetic diversity at both the fine and coarse spatial scales should exist. Comparatively, if parallel responses of both interacting assemblages to macro abiotic gradients were detected, we could conclude that the turnover patterns would be only correlated at large spatial scales. Separation of the impacts of macro climatic/environmental variables on community dissimilarities remains a challenge that has been rarely explored in the large-scale patterns of species richness. In the context of insect communities, we expect substantial compositional changes between regions (if historical bio-geographical effects are important) and along abiotic gradients within regions (if insects generally have specific abiotic requirements, such as temperature) $[29,30]$. If insect speciation has been largely induced by allopatric host shifts of specialized insect species, we can expect a complete change in insect assemblage associated with shifts in plant assemblage [31, 32].

Many studies has mostly focused on plant-herbivore $[6,29,33-35]$ and -pollinator interactions [36], relationships that are specialized more or less to some extent. Exceptions are Hulcr et al. [37], Hulcr et al. [3], $\mathrm{Wu}$ et al. [38], Wende et al. [39], and Vogel et al. [2], who studied detritivorous bark and saproxylic beetles, which are loosely associated with their hosts. Their studies investigated the impact of host specificity on beetle community composition within the same climatic region, disregarding environment gradients, and some found host specificities of plants played an important role on beetles' composition [2,39], some found not $[3,37]$. Furthermore, the study aiming to explore the relationships between hosts and detritivorous saproxylic beetle community found that proportion of habitat specialists decreased, whereas proportion of habitat generalists increased with increased wood decay succession [38]. That is, the interactions of detritivorous insect assemblages with their hosts along steep environmental gradients have rarely been studied, and whether detritivorous insects exhibit similar trends to herbivores and pollinators with various host dependence extent is still unknown.

Bark beetles (Coleoptera: Curculionidae, Scolytinae, and Platypodinae) are the most important phloem-/ wood-feeding guilds that threaten forests worldwide. There are two distinct groups of Scolytinaes, bark beetles and ambrosia beetles. Bark beetles are typically phloem feeders, while ambrosia beetles typically bore into the wood and feed on the symbiotic xylosaprophagous ambrosia fungi that the beetles introduce into the trees [40, 41]. Exploitation of the fungi as food source has allowed some ambrosia beetles to use a wide variety of hosts [37, 42]. The effects of tree diversity, host specificity, and structural heterogeneity of habitat on bark beetles at a local scale and along a flat environmental gradient have been well studied [2, 3, 37, 42-44]. The general goal of this paper was to derive environmental and spatial models to account for patterns of variation in the co-occurrence of bark beetles across a steep elevation gradient in the Yunnan Province, Southwest China. We aimed to compare the relationship between tree's host specificity and bark beetle turnover among different climatic sub-regions embedded within a relatively homogeneous abiotic gradient. We hypothesized that divergent co-occurrence distribution patterns between host trees and bark beetle assemblages across huge environmental differences explain a weak relationship among these two groups, (2) trees' host specificity plays a minor role in structuring bark beetle diversity distribution across regional elevation gradient compared with abiotic environmental factors, but not for local scale; and (3) $\beta$-diversity of both bark beetles and trees will be similar and there is a parallel spatial structuring of bark beetles with host trees along the steep elevation gradient, but with a much wider niche overlap compared with those host tree communities. Furthermore, we also predicted that $\beta$-diversity values of bark beetles will be significantly lower than their host trees across regional elevation gradient in the present study. 
Table 1 Results of Beta regression in Generalized linear models testing for the relationships between both beetles and trees composition variation at regional and local spatial scales with sampling elevation gradient respectively

\begin{tabular}{|c|c|c|c|c|c|c|c|c|c|c|}
\hline \multirow[t]{2}{*}{ Scales } & \multirow[t]{2}{*}{ Group } & \multicolumn{3}{|c|}{ Horn_similarity } & \multicolumn{3}{|c|}{ Bray_dissimilarity } & \multicolumn{3}{|c|}{ Beta_deviation } \\
\hline & & $\bar{Z}$ & $R^{2}$ & $P$ & $\bar{Z}$ & $R^{2}$ & $P$ & $\bar{Z}$ & $R^{2}$ & $P$ \\
\hline Regional & Trees & -5.905 & 0.038 & $<0.001$ & 0.477 & 0.004 & 0.634 & 0.94 & 0.020 & 0.347 \\
\hline Yunnan & Beetles & 9.295 & 0.287 & $<0.001$ & -15.14 & 0.830 & $<0.001$ & -15.77 & 0.845 & $<0.001$ \\
\hline \multicolumn{11}{|l|}{ Local } \\
\hline Tropics & Trees & 2.430 & 0.157 & 0.015 & -5.341 & 0.684 & $<0.001$ & -6.184 & 0.700 & $<0.001$ \\
\hline Bubeng & Beetles & -2.127 & 0.149 & 0.033 & -1.509 & 0.133 & 0.131 & -1.502 & 0.129 & 0.133 \\
\hline Subtropics & Trees & 5.135 & 0.505 & $<0.001$ & -5.474 & 0.667 & $<0.001$ & -5.913 & 0.700 & $<0.001$ \\
\hline Ailaoshan & Beetles & -3.326 & 0.277 & $<0.001$ & -1.406 & 0.117 & 0.160 & -1.404 & 0.115 & 0.160 \\
\hline Temperates & Trees & -0.826 & 0.023 & 0.409 & -3.585 & 0.440 & $<0.001$ & -4.025 & 0.549 & $<0.001$ \\
\hline Yulongxueshan & Beetles & 3.751 & 0.452 & $<0.001$ & -2.358 & 0.272 & $<0.05$ & -2.292 & 0.263 & 0.022 \\
\hline
\end{tabular}

\section{Results}

\section{Tree and beetle composition}

A total of 64,710 bark beetles from 264 species were collected from all three sub-regions (see Additional file 2: Appendix file 1). The collection included 62,245 individuals representing 212 species of the Scolytinae group and 2465 individuals representing 52 species of the Platypodinae group. Of these, 25,676 individuals (180 species) were collected in tropical Bubeng; 33,781 individuals (116 species), in subtropical Ailaoshan; and 5,253 individuals (43 species), in cold temperate Lijiang. The five most abundant bark beetle species, which accounted for $51 \%$ of the total individuals collected were, in order of importance, Scolytoplatypus raja, Scolytoplatypus blandfordi, Xylosandrus crassiusculus, and two as yet unidentified species, Microperus sp. YUN08 and Xyleborinus sp. YUN02. A total of 2184 tree individuals from 213 species were recorded (see Additional file 3: Appendix file 2), including 1180 individuals from 137 species in tropical Bubeng, 795 individuals from 60 species in subtropical Ailaoshan, and 209 individuals from 18 species in temperate Yulongxueshan, Lijiang.

\section{Species turnover comparison between beetles and trees}

$\beta$-diversity of tree communities measured through Horn similarity method was significantly decreased with the elevation increased (GLMs, $\mathrm{Z}=-5.905, R^{2}=0.0376$, $P<0.001$ ) at the regional scale (Table 1 ) but with a very low $R^{2}$ value. Contrary to this, $\beta$-diversity of beetles significantly increased with elevation gradient (GLMs, $\mathrm{Z}=9.295, R^{2}=0.2868, P<0.001$ ) (Table 1 ). Horn similarity $\beta$-diversity values of beetle assemblage were significantly higher than those of trees in three sub-regions, along the gradient from tropical to temperate $(P<0.0001$; Fig. 2a-I). At the local scale, Horn $\beta$-diversity of trees and beetles also showed a significantly different pattern with elevation gradients in tropic, subtropics and temperate respectively. The opposite pattern at regional spatial scale was not similar with that showed in tropical Bubeng and subtropical Ailaoshan (Table 1). However, it was similar only for the upper altitudinal floor (Fig. 2a-IV), with a decreasing $\beta$-diversity of tree communities and increasing $\beta$-diversity of beetles when the elevation increased. Furthermore, most of the Horn similarity $\beta$-diversity values of beetle assemblages were statistically significant higher than those of trees communities (Fig. 2a-II, III \& IV, $P<0.001)$, except for values at $2600 \mathrm{~m}$ in the subtropical areas (ns, Fig. 2a-III). When we compared the Horn similarity values of beetles and trees separately, they did not show a uniform tendency neither at regional scale, from tropical to temperate areas nor at local scale, from low to high elevation (Fig. $2 \mathrm{a}$ and Table 1).

The observed $\beta$-diversity values of tree assemblages measured through Bray dissimilarity method were significantly higher than those of beetles $(P<0.01$; Fig. $2 b)$. Almost both trees and beetles observed Bray $\beta$-diversity values showed a decreased tendency with elevation increased $(Z<0$; Table 1$)$ but except $Z$ value of 0.477

(See figure on next page.)

Fig. 2 Turnover (Horn similarity) of insect species (bark beetles, yellow) and tree species (green) between Flight intercept trap sampling plots $(25 \times 20 \mathrm{~m})$ at one regional scale Fig. $2 \mathrm{a}$ (I) and three local scales (II, III \& IV) in Yunnan Province. Figure 2b shows the observed $\beta$-diversity calculated through Bray-Curtis dissimilarity method. Figure $2 c$ shows the values of $\beta$-deviations through null model method which is based on the differences between observed $\beta$-diversity and a standardized effect size of $\beta$-diversity that controls sampling from the regional species pool. Boxes represent the median and 25th/75th percentile, and whiskers extend to 1.5 times the interquartile range 

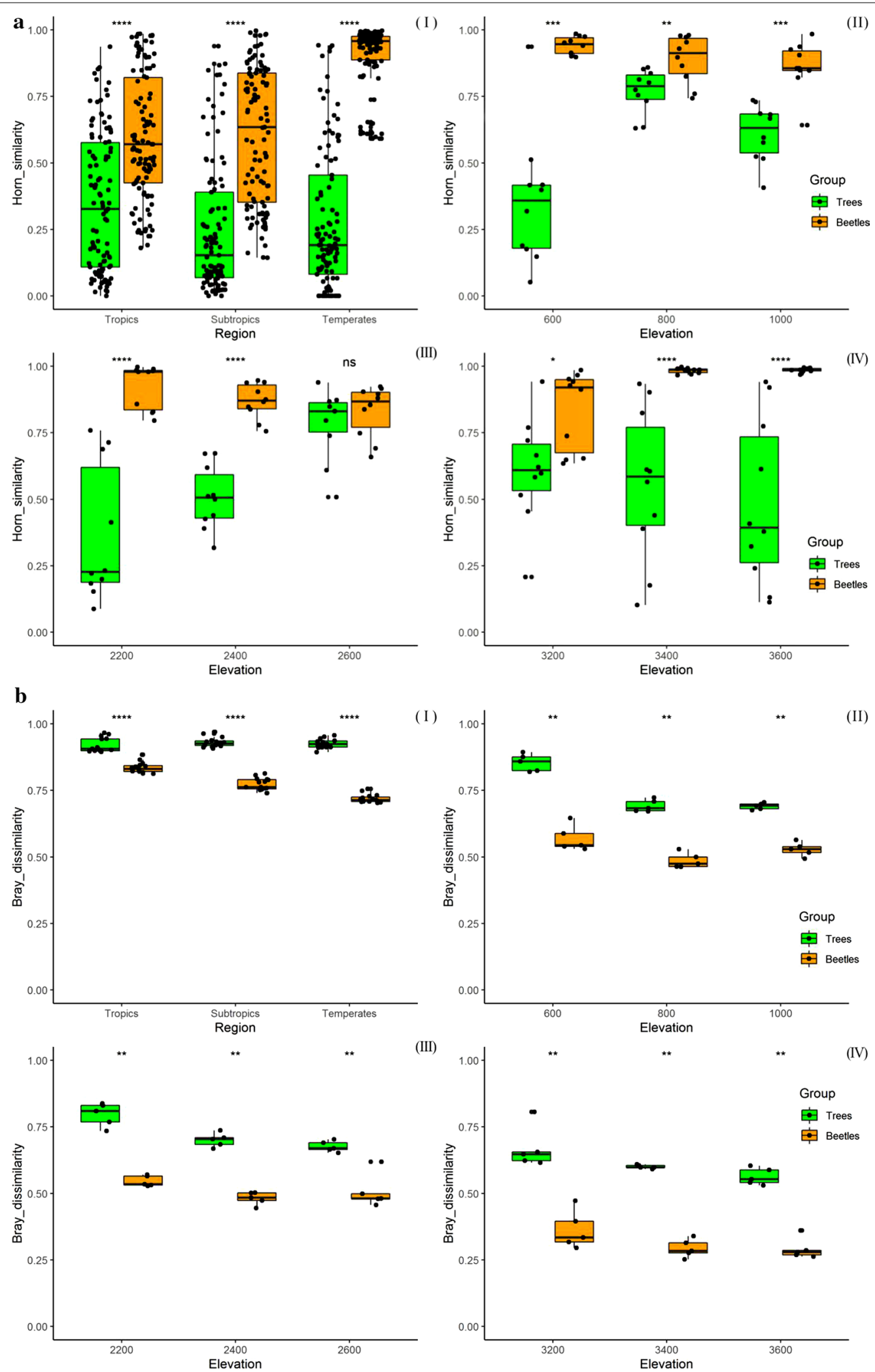

Fig. 2 (See legend on previous page.) 

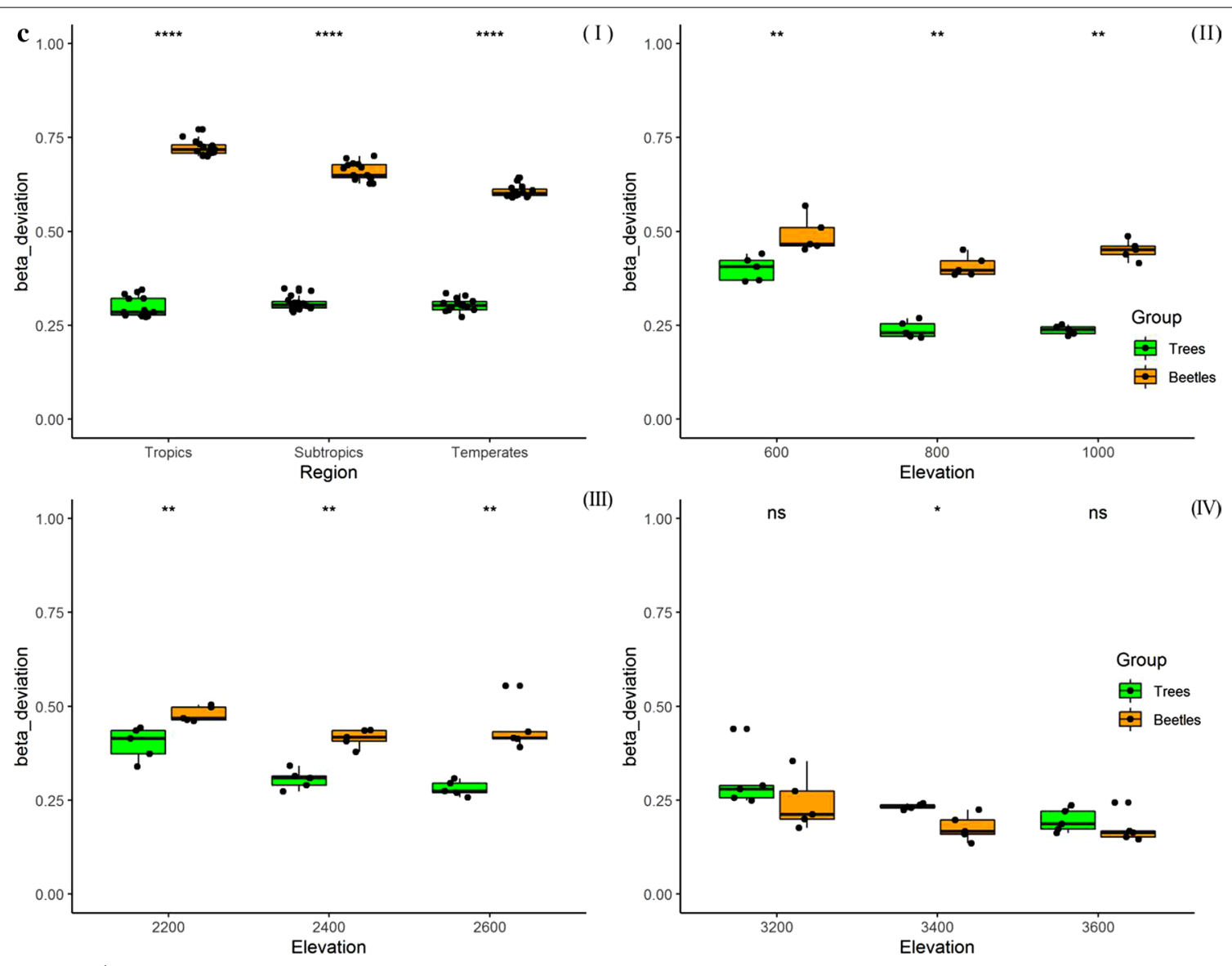

Fig. 2 continued

for trees community at regional scale (Table 1 ). The $R^{2}$ values of coefficients between both trees and beetles with elevation gradients also showed a statistically significant different pattern between regional and local spatial scales (Table 1 ). Bray dissimilarity $\beta$-diversity values of beetle assemblage were significantly lower than those of trees at regional scale, along the gradient from tropical to temperate $(P<0.0001$; Fig. $2 \mathrm{~b}-\mathrm{I})$. At the local scale, Bray $\beta$-diversity of both trees and beetles showed a decreased pattern with elevation increased $(\mathrm{Z}<0$; Table 1; Fig. 2b-II, III \& IV). Nonetheless, it was not significantly for beetles in tropical Bubeng $\left(R^{2}=0.133, \quad P=0.131\right)$ and subtropical Ailaoshan $\left(R^{2}=0.117, P=0.160\right)$. These patterns were not similar with Bray dissimilarity values of trees at regional scale and which showed a non-significantly increased pattern from tropics to subtropics and temperate $(Z=0.477$; $P=0.634$ ). The abundance $\beta$-null deviation measures showed an almost similar pattern with the $\beta$-diversity values through the method of Bray dissimilarity index calculation, and a large proportion of negative $\mathrm{Z}$ values means a decreased relationship with elevation gradient but except $\mathrm{Z}$ value of 0.94 for trees community at regional scale (Table 1; Fig. $2 \mathrm{~b}$ and c). If we concentrated this point at local scales, $\beta$-null deviations of tree communities were significantly decreased with elevation gradient $(Z<0, P<0.001$; Table 1$)$. Although $\beta$-null deviation of beetle assemblages were also decreased with elevation gradient $(Z<0$; Table 1$)$, it was not significantly correlated $(P>0.01$; Table 1$)$. The most of beetles $\beta$-null deviation values were statistically significant higher than those trees communities at both regional and local scales $(P<0.01$; Fig. $2 c-$ I, II \& III) but except for those at 3200 and $3600 \mathrm{~m}$ plots in temperate areas (ns, Fig. 3c-IV).

\section{Correlations of beetle turnover with tree community}

After removing the influence of spatial distance, RDA revealed that abundance of the 21 most important tree species of the 211 recorded explained $10 \%$ of the variation in wood-boring beetle community composition separately, spatial distance explained $1 \%$, and $12 \%$ remained unexplained. Moreover, 14 phylogenetic PC axes (accounting for $90 \%$ of variation in tree phylogenetic 
Table 2 Results of redundancy analyses testing for the influence of tree species composition and phylogenetic turnover on the community composition of bark beetles in Yunnan Province, China, while removing the influence of spatial distance between sampling units (FITs)

\begin{tabular}{|c|c|c|c|c|c|}
\hline & & $\begin{array}{l}\text { Number of species/phylogenetic PC } \\
\text { axes included }\end{array}$ & $F$ & $P$ & $\begin{array}{l}\text { Proportion } \\
\text { explained }\end{array}$ \\
\hline & & Regional scale & & & \\
\hline & & Yunnan Province & & & \\
\hline Beetles & Tree species & $21 / 211$ & 2.561 & 0.001 & 0.10 \\
\hline \multirow[t]{3}{*}{ Beetles } & Tree phylogenetic & $14 / 45$ & 2.275 & 0.001 & 0.07 \\
\hline & & Local scale & & & \\
\hline & & Tropics (Bubeng) & & & \\
\hline \multirow[t]{2}{*}{ Beetles } & Tree species & $7 / 137$ & 3.616 & 0.001 & 0.34 \\
\hline & & Subtropics (Ailaoshan) & & & \\
\hline \multirow[t]{2}{*}{ Beetles } & Tree species & $4 / 60$ & 1.258 & 0.188 & 0.03 \\
\hline & & Temperates (Yulongxueshan) & & & \\
\hline Beetles & Tree species & $4 / 18$ & 1.875 & 0.001 & 0.15 \\
\hline
\end{tabular}

$F$ statistics to test the significance of variables were calculated using the iterative 'anova.cca' in 'vegan'. Regional spatial scale covers all of three local sampling sites from tropical Bubeng to subtropical Ailaoshan and to temperate Yulongxueshan

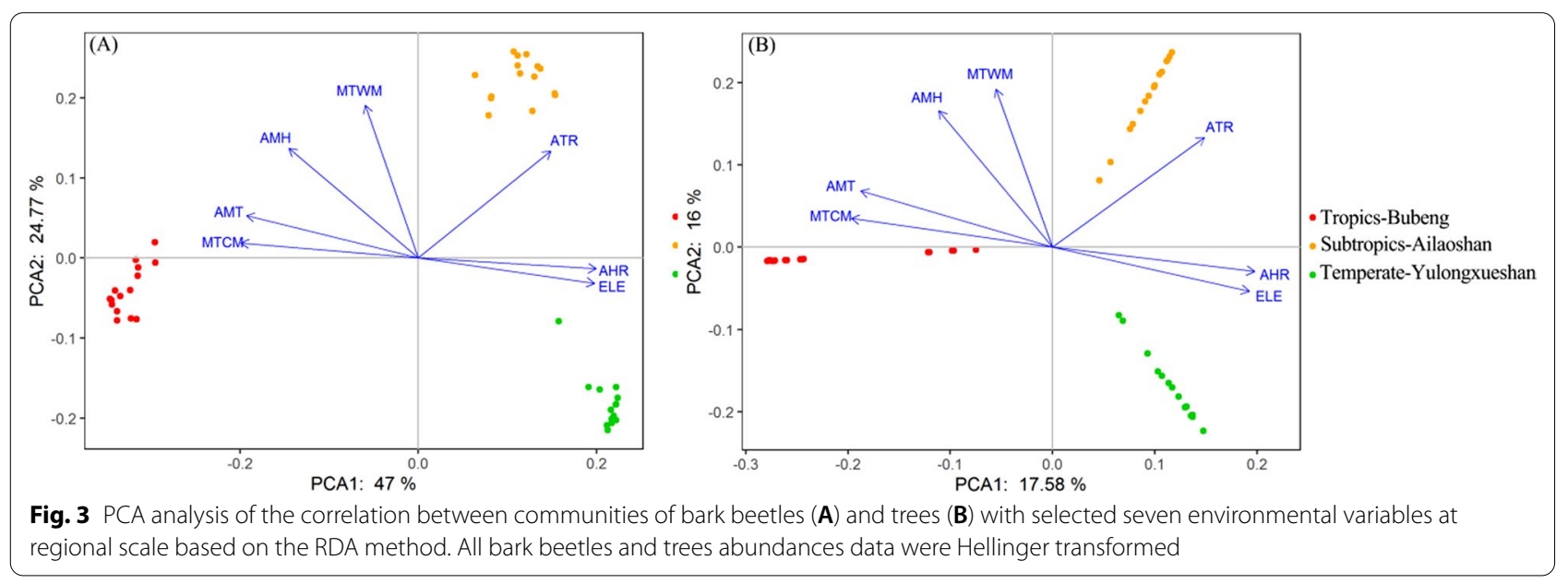

turnover between sampling units) explained only $7 \%$ of the variation in bark beetle community composition separately. At the local scale, the selected tree species abundance after forward selection procedure in RDA analysis separately explained $34 \%, 3 \%$, and $15 \%$ of beetles composition variation in the tropics, subtropics, and temperate area, respectively (Table 2).

Species distribution ordinations between beetles and trees As shown in Fig. 3, PCA analyzes showed that all seven selected environmental variables have statistically significant cor-relationships with species distribution patterns for both trees and beetles communities $(P<0.05)$. Among them, the variables of elevation gradients (ELE) and relative annual humidity range (AHR) played a statistically significant negative role on species distribution. Considering even all environmental variables were spatial auto-correlated with elevation gradient, it's not surprisingly that the minimum temperature of the coldest temperature (MTCM) have a positive impact on species distribution from temperate to tropical areas for both trees and beetles communities $(P<0.05$, Fig. 3). More importantly, at the regional scales, the recorded environmental variables had a significantly higher explanation power for beetles than trees communities in the present study. It showed that two axis, represented by PCA1 and PCA1 reached to $47 \%$ and $24.77 \%$ separately for beetles group (Fig. 3A) but only $17.58 \%$ and $16 \%$ separately for trees (Fig. 3B). 


\section{Discussion}

Co-occurrences of bark beetles weighted as $\beta$-diversity did not all show a statistically significant correlation with both trees species and phylogenetic turnover at all three sub-regions from tropical to temperate areas. Those divergent co-occurrence distribution patterns between host trees and bark beetle assemblages across huge environmental differences explain a weak relationship among these two groups. This result suggests a minor role of host specificity on bark beetle diversity distribution at the community level. Several studies on comparison of insect host dependence among different climatic regions have presented diverse results. For example, a low host specificity of herbivorous insects in a tropical forest [6], species turnover of insect herbivore communities (leaf-chewing and sap-sucking guilds) in three Brazilian ecoregions was not related to tree richness [45], tree species had a lower impact on saproxylic beetle communities compared to abiotic factors (sun exposure) [2] and a greater turnover in caterpillar species composition in tropical faunas than in temperate faunas [46]. It is still reasonable to infer a relatively weak biotic interaction between trees and their hosted bark beetles when comparing the impacts of huge climatic differences from tropical to temperate climatic gradients. That is, elevation gradients, the most important environmental variable, are major drivers which structuralized the species distribution patterns at regional scale for both beetles and trees.

Admission of the minor role that insect-plant interactions play on large-scale hosted species turnover does not imply denial of the associations between different nested trophic assemblages. Tree host specificity was an important topic in biodiversity estimation and maintenance at local scale $[8,47,48]$, although it is difficult to measure host specificities directly. First, comparing the strength of tree host specificities among different climatic areas generally ignore the impacts of the species pool and has led to diverse interpretations $[6,42,46]$. Second, simply using tree diversity as a surrogate to estimate their hosted herbivorous insect diversity $[7,8,34,37,38,49]$ is too coarse to get convincing unbiased results when considering the mixed effects of spatial environmental variables. Most of the different insect assemblages have shown a loose relationship with their hosts, and host shifting is a common phenomenon in nature [50]. If we further explore mutualistic interactions in detail, most of these interactions present a broad range of partners, even if it allows for ineffective partners to persist [15]. For bark beetles, as a major group of wood decomposers, a large part of this taxon has a strong dependence on their mutualistic fungus. It means external biotic selection pressure caused by the tree host specificity might be minor compared with other factors. Current studies suggest that extremely specialized or generalized insect species communities, whether detritivores or herbivores, only account for a minor proportion of the total assemblages, and most species are concentrated in the center group of the host dependence sequence [6, 7]. In this context, bark beetle diversity distribution was also probably rarely impacted by tree host specificities at the local spatial scale, especially when considering that limited host dependence will decrease quickly during the wood decomposition process [38].

Additionally, organism characteristics represented by dispersal type and ability play an important role on species diversity distribution across a large climatic gradient [21]. This dispersal ability, represented as access to dispersal or colonization over a relevant time interval, was another important component to mediate the actual spatial area of distribution of the species [51]. It is possibly that co-occurrences of interacted assemblages vary widely among organisms with different dispersal abilities [20, 23], when we did cross-taxon's $\beta$-diversity comparison across a same environmental gradient. The present study showed a clear pattern that tree dispersal via seeds had a much higher turnover than the actively mobile bark beetles. It confirmed that species characteristics, reflecting the autecology of individual organisms, have a statistically significant effect on $\beta$-diversity distribution. Because the high dispersal ability significantly reduced the plot sampling difference, it should have a negative impact on $\beta$-diversity. Nonetheless, Harrison et al. [52] compared cross-taxon' $\beta$-diversity with different dispersal ability for British biota ranging from flying birds to insects and plants. They showed that $\beta$-diversity is more constrained by species' ecological niche requirements than by the species dispersal ability, and it could be negligible for statistical model comparison. The organisms in this study have huge differences in dispersal ability, and furthermore, the $\beta$-diversity of a specific biological assemblage might be controlled through a series of combined and interacting factors at different spatial and temporal scales. Considering that species dispersal ability can reflect species environment adaption flexibility to some extent [53], when species both adapt and disperse at the same time interval, dispersal and adaptation cannot combine positively to affect biodiversity maintenance [54]. Such conflicts can be observed and it gives us an idea that species diversity distribution is a paradox of mixed factors that cannot be easily and clearly separated. Although it is valuable to get a deep insight for comparisons of dispersal and adaptation among different biotic assemblage, our study presented a statistically significant different pattern of $\beta$-diversity between trees and their hosted bark 
beetles attributed most probably to those dispersal ability and type variation.

As we try to explore the major underlying mechanism that mediated the relationships between trees and the hosted bark beetles, many other technical factors, including effectiveness of sample size, spatial grain of sampling, bias of statistical method used, and data weight of each biological individual, can mix patterns that are not interpreted easily. Bennett and Gilbert [55] compared the differences between multi-site dissimilarity and traditional null model methods, and Engel et al. [56] used the coverage-based rarefaction method to overcome the species pool dependence of $\beta$-diversity bias toward to null hypothesis. No matter what kind of specific method is used nor how many effective samples were adopted, it is definitely a challenge to arrive at a convincing explanation based on statistical inference directly. Considering that although from a human perspective of the "local" scale, is standardized to be defined by $20 \times 25 \mathrm{~m}$ plots in the present study, from the "point of view" of beetles and trees, these plots are not "equally local", and the way these taxa perceive the environmental heterogeneity at this spatial scale could differ greatly just because of differences in their body size, which might impact on the human perception of their species turnover patterns. Furthermore, when we look back to compare the basic physiological differences between trees and beetles, tree distribution depends more heavily on soil water and nutrient content than do beetles. Both assemblages faced the same temperature gradient at a macro scale; bark beetles clearly have a broader low-temperature tolerance ability compared with that of tree communities because the majority of the beetle's life cycle is confined to within the decaying tree stem. That is, if we did comparisons with some other insect assemblages which are not confined to wood boring ecological system, for examples, ants community [57] and herbivorous insects [58] in mountainous areas of Neotropical area, $\beta$-diversity of latter two groups, and which were mainly generated through turnover rate, were strongly influenced by variables correlated with elevation gradient, habitat structure and local resource distribution. From the data of species co-occurrence distribution in the present study, some of the beetle species collected in tropical Bubeng were also found in subtropical Ailaoshan, and some subtropical species were also occurred at temperate. It suggests that both host dependence and temperature gradient from tropical to subtropical and temperate areas do not have a statistically significant impact on bark beetle distribution. Thus, the parallel co-occurrence distribution pattern between bark beetle and tree assemblages at regional scale are most probably attributed to macro climatic gradient, and without relationships to trees host specificities clearly.
Finally, as previous study demonstrated that some bark beetle species rely on ethanol for host tree colonization because it promotes the growth of their fungal gardens while inhibiting the growth of "weedy" fungal competitors [59], it seems explained the most of bark beetle specimens were collected at the understory FITs in tropical and subtropical sampling areas. Because the tree stems at understory are generally relative bigger and older than canopies' woods and can emit micro dose ethanol out from bark within dim light environment. The $75 \%$ alcohol used here might has influenced the community composition dramatically, making the ethanol-attracted component such as the genera of Scolytoplatypus and Xylosandrus are much more prevalent in our collections. As regarded to statistically non-significant differences of bark beetles collected between canopy and understory FITs in cold temperate, it was most probably attributed to the relative lower density of wood stems over there and similar light conditions among them.

\section{Conclusions}

In this study, we compared co-variations in $\beta$-diversity of bark beetles and their host tree communities from the tropics to cold subalpine habitats in Yunnan, SW China. The results showed that species turnover of both trees and bark beetles have an opposite pattern along the climatic proxy (represented by the elevation gradients) at the regional scale, but not at local spatial scales. This pattern further supported the hypothesis according to which emphasis is on macro-climate influences on local biotic interactions between trees and hosted beetle communities, whereas local biotic relations represented by host specificities dependence are regionally conserved. At a confined spatial scale, cross-taxa comparisons of $\beta$-diversity highlighted the importance of simultaneous impacts from both extrinsic factors related to geography and environment, and intrinsic factors related to organism characteristics. The effects of diversity of tree abundance and phylogeny on bark beetle diversity were to a large extent indirect, operating via changes in beetle abundance through spatial-temporal dynamics of resource distribution. Tree host dependence, which was considered and represented by host specificities, plays a minor role on the hosted beetle community in this concealed wood decomposing interacting system.

\section{Methods}

\section{Forest plots from tropics to temperate}

The study was performed in the Yunnan Province, Southwest China, located centrally to the north of the Indo-China Peninsular (Fig. 4A). The area is extremely diversified in habitats and biodiversity, and it is one of the 25 biodiversity hotspots in the world [60]. The region 


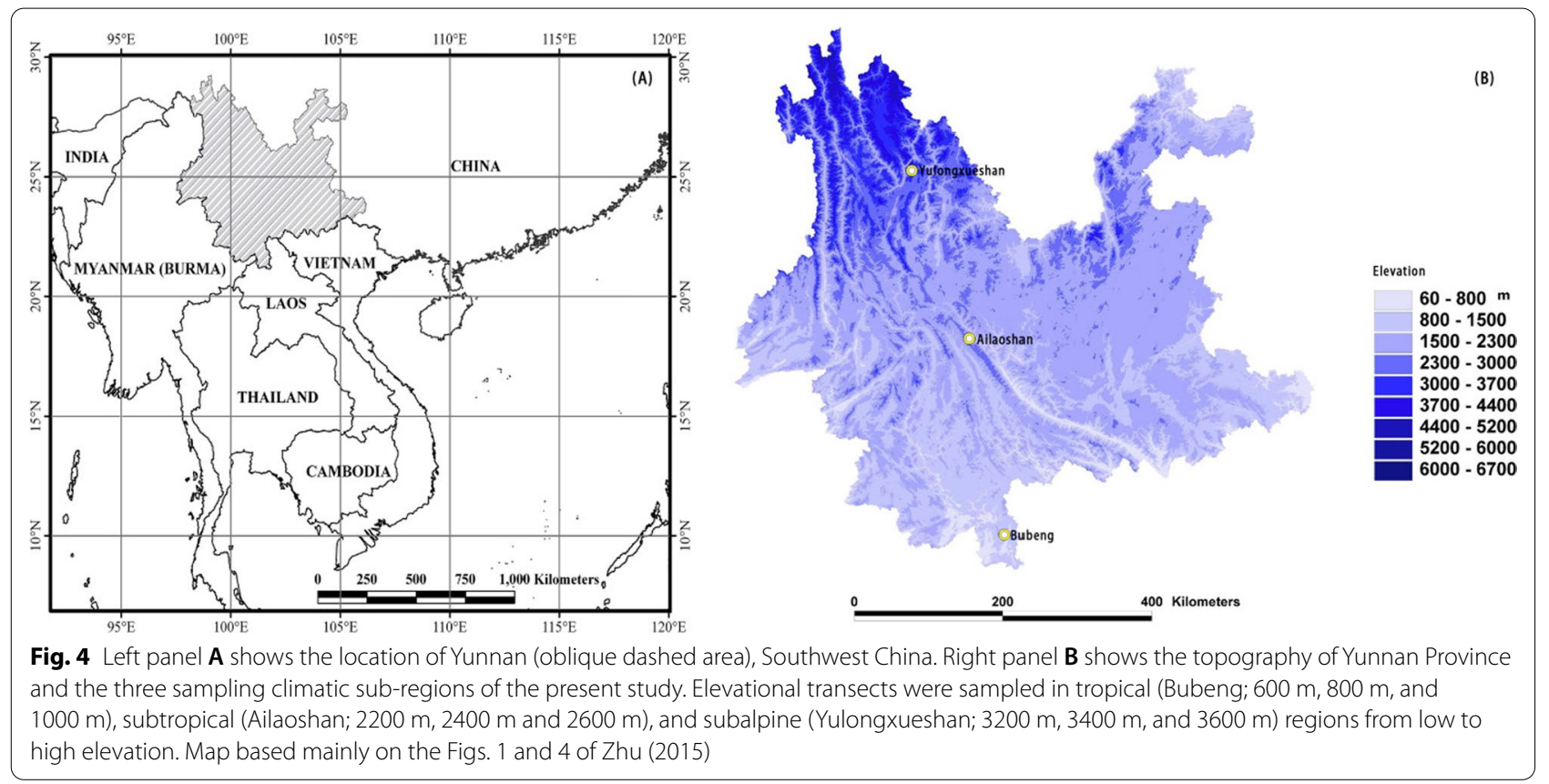

sampled in this study is also part of the 'Eastern Himalaya-SE Tibet hotspots', and area with up to 3000-5000 or more vascular plants per $10,000 \mathrm{~km}^{2}[61,62]$. The impacts of the tropical monsoonal climate and complex mountainous topography cause this area to be covered with diversified vegetation, from tropical monsoonal rainforest to temperate coniferous forest, along elevation and altitudinal gradients.

We sampled bark beetles from three typical biomes: tropical monsoonal rainforest in Bubeng (Xishuangbanna); subtropical mid-mountain moist evergreen broad-leaved forest at Ailaoshan (Puer); and cold temperate spruce-fir forest at Yulongxueshan (Lijiang) from low to high elevation (Fig. 4B). Three big permanent plots for long-term ecological research with areas of 20 or 25 ha have been established in recent years, and a standardized vegetation inventory has shown that the area at Bubeng is hyper-diversified [468 woody species, [63]], the Ailaoshan plot is median-diversified [103 woody species, [64]], and the coniferous forest at Yulongxueshan is lowdiversified [62 woody species, [65]]. Basic environmental information of each sampling plot are listed in Additional file 1: Table S1.

\section{Sampling design}

A hierarchical and spatially nested sampling approach was used. To compare the impact of elevation on the $\beta$-diversity of bark beetle species across the three different sub-regions, we established three elevational transects in each sub-region, close to the permanent plots aforementioned. The experiment was performed from March 2018 to May 2019. In each area, we studied the same ecological amplitude of elevation gradient and covered a range of almost 400 elevation meters. Each transect included five forest plots with an intermediate cell size of $25 \times 20 \mathrm{~m}$, all of which were equipped with devices for collecting beetles. All five forest plots at each transect were oriented parallel to the respective contour lines and were at least $40 \mathrm{~m}$ apart. That is, each sub-region had fifteen cell sizes of $25 \times 20 \mathrm{~m}$ plots and three sub-regions from tropical to temperate climate totally included 45 sampling plots of vegetation.

The tropical transects were located in Bubeng, Xishuangbanna $\left(21^{\circ} 61^{\prime} \mathrm{N}, 101^{\circ} 58^{\prime} \mathrm{E}\right)$. This area borders Myanmar in the southwest and Laos in the southeast. Average annual temperature and precipitation are $22{ }^{\circ} \mathrm{C}$ and $1500 \mathrm{~mm}$, respectively. The rainy season occurs from May to October and the dry season from November to April, with approximately $80 \%$ of the annual precipitation occurring in the rainy season. Heavy fog frequently occurs in the lowlands and valleys in the mornings during the dry season, and this fog expands the northern limit of the tropical rain forest from Southeast Asia. Three separated elevation transects (at 600, 800, and $1000 \mathrm{~m}$ ) were established, based on vegetation and topography.

The subtropical transects were established in Ailaoshan, Puer $\left(24^{\circ} 53^{\prime} \mathrm{N}, 101^{\circ} 03^{\prime} \mathrm{E}\right)$. Average annual temperature and precipitation are $11{ }^{\circ} \mathrm{C}$ and $1900 \mathrm{~mm}$, respectively. The dry season occurs from December to April and the rainy season from June to October. The 
area encompasses a large tract of evergreen broad-leaved forests primarily dominated by Lithocarpus and Castanopsis species at mid-elevation (ca. 2200-2600 m a.s.l.) with a dense or sparse understory of bamboo and with Rhododendron dwarf forest toward higher elevations. Three separated elevation transects (at 2200, 2400, and $2600 \mathrm{~m}$ ) were established based on their vegetation and topography.

The cold temperate transects were established at Yulongxueshan, Lijiang $\left(27^{\circ} 14^{\prime} \mathrm{N}, 100^{\circ} 23^{\prime} \mathrm{E}\right)$. Average annual temperature and precipitation are $5.5{ }^{\circ} \mathrm{C}$ and $1600 \mathrm{~mm}$, respectively. The rainy season occurs from July to September and the dry season from December to March of coming next year. The area encompasses a large tract of temperate coniferous forest with an understory formed primarily with Berberidaceae, Caprifoliaceae, and Rosaceae species. Trees of the families Pinaceae and Fagaceae dominate the canopy equally. Three separated elevation transects were established (at 3200, 3400, and $3600 \mathrm{~m})$.

\section{Insect sampling and diversity estimation}

Beetle sampling was performed using modified aerial collectors both in the canopy and understory of each forest plot at all sites. Aerial collectors, also called flight interception traps (FITs), were constructed with two hard transparent plastic plates $(50 \times 35 \mathrm{~cm} ; \mathrm{H} \times \mathrm{W})$, which were arranged crosswise and fixed upon a plastic bowl $(35 \times 30 \mathrm{~cm} ; \mathrm{D} \times \mathrm{H})$. A round plate of soft transparent plastic (45- $\mathrm{cm}$ diameter) was fixed over each FIT as a roof to prevent too much precipitation entering the trap during the rainy season. Within each plot, one trap was installed on tree branches in the canopy, at a height of 10-30 m above the ground, and a second was placed in the understory area at a height of $2 \mathrm{~m}$. The FITs were fixed with nylon ropes to prevent the spillover of antirotting liquids by the wind. The collection bowls of the FITs were filled with a mixture of $75 \%$ alcohol and blue colored anti-freeze (ethylene-glycol) at a proportion of 1:2 v:v. Ten FITs were used in each transect, and a total of 90 FITs were installed across all three investigated regions.

Because of the large differences in climate among the three regions, the trap collection activity started at different times in each region; however, the sampling always covered the period of peak beetle activity and lasted at least one whole year. We conducted field work at Bubeng, from the beginning of April 2018 to the end of March 2019; at Ailaoshan, from the beginning of May 2018 to the end of April 2019; and at Yulongxueshan, from the beginning of June 2018 to the end of May 2019. At all plots, traps were emptied every 10 days during the collection period (with a few exceptions, where the traps were destroyed by strong winds or collection was impossible because of heavy rains). The beetle specimens were preserved in $70 \%$ ethanol and were preliminary sorted to morph-species level in the laboratory. Later all morphspecies were further determined by Prof. Roger Beaver in Thailand and Dr. Heiko Gebhardt in Germany to the species level. Data analyses were based on numbers of species and individuals combined from all trap times per plot and the total counts from all collection periods. Voucher specimens of the collected beetles were temporarily stored in the laboratory at the Honghe University.

Both multi-sites dissimilarity and null model methods were used to calculate the $\beta$-diversity of beetle's community. The first method used the package 'vegetarian' [66] in R 3.6.3 (R Core Team, 2013). The Horn similarity index was used as recommended by Jost [67], because it was the only overlap measure that was not disproportionately biased toward rare or common species. This index is considered to be a "true" measure that quantifies effective species overlap between sampling units [68]. The Horn similarity index was defined as: ${ }^{1} D_{\beta}=(\ln 2-$ $\left.H_{\beta S h a n}\right) / \ln 2$, in which $H_{\beta \text { Shan }}$ is the Shannon entropy based on Hill numbers and $\beta$-diversity is therefore independent of $\alpha$-diversity [67]. To overcome the demographic stochasticity of the sampling plots, a null model method was used to simulate species assemblages for each FIT by randomly sampling individuals from the regional species pool, according to the relative species abundance in the regional pool and the total number of individuals [69-71]. The dissimilarity matrix was calculated using the Bray-Curtis method, which takes account of species relative abundances [68]. From 1000 iterations of the null model, we calculated a standardized effect size $(\beta$-deviation) as the difference between the observed and mean expected dissimilarity, divided by the standard deviation of expected values. This formula retains the observed abundance distribution but randomizes the location of sampled individuals. The $R$ code for $\beta$-null deviation calculations referenced the methods provided by Stegen et al. [72] and Tucker et al. [73].

The canopy and understory FITs were combined to give the smallest sampling unit for the estimation of $\beta$-diversity among three regions. Pairwise Horn similarities were calculated between all plots from beetle species abundance lists compiled for each sampling plot. The function 'sim.table' in 'vegetarian' was used for this purpose. Given that we were computing and comparing turnover between identical sampling units in all cases, it was not necessary to consider the species accumulation curve to assess whether sampling was adequate. 


\section{Tree sampling and diversity estimation}

The vegetation data collection was performed in April and May of 2019. The five $25 \times 20 \mathrm{~m}$ forest plots established for the insect sampling at the three study regions were also used for the vegetation survey. Identical field methods were used to survey each plot. All plots were established as far away as possible from the large canopy gaps created by recent anthropogenic and natural disturbances. In each plot, we measured the abundance of each tree species (or morphospecies) $\geq 5.0 \mathrm{~cm}$ diameter at breast height $(1.3 \mathrm{~m})$. Seedlings were excluded. All sampling methods used in present study comply with the instructions of the Center for Tropical Forest Science (CTFS; http://www.ctfs.si.edu/) for collection of long-term, large-scale forest data from the tropics [76] and with those from the Chinese Forest Biodiversity Monitoring Network (http://www.cfbiodiv.org/). When establishing plots on slopes, we positioned the plot center line perpendicular to the slopes to minimize elevation gradients within the plots. As sampling included similar numbers of plots spanning small and large spatial distances, we were able to compare the potential influence of spatial limitation between regions at similar scales, including extents that encompass typical dispersal distances (seed shadows) from tropical to temperate vegetation.

Tree abundances were recorded for each plot. Horn similarity matrices were constructed using plots and transects as sampling units in the same manner as described for the beetles. The family and genus names of all the studied species (216 species in total) in the APG III system were obtained using the $R$ package 'plantlist' [74], and their phylogenetic relationships were examined using the online Phylomatic tool ([75]; www. phylodiversity.net/phylomatic/) based on the angiosperm consensus tree from Davies et al. [76]. Similarity matrices were then constructed for plant phylogenetic $\beta$-diversity [PhyloSor Index [77]] with the function 'phylosor' in 'picante' package in R [78]. PhyloSor is a modification of the Sørensen similarity index that quantifies phylogenetic similarity of communities as the proportion of shared phylogenetic branch-lengths between two samples. If the length of shared branches is high, communities comprise phylogenetically closely related taxa.

\section{Environmental factors}

We recorded air temperature and humidity data at each of the transects within the three study regions every 30 min using a thermo-logger (DS1923Hygrochron iButton $^{\circledR}$, Maxim, CA, USA) from April 2018 to May 2019, during the period of insect collection. A total of nine environmental data loggers were used; each device was fixed at one of the five canopy FITs in each transect. A total of seven variables were measured, including annual mean temperature (AMT) and humidity (AMH), annual temperature (ATR) and humidity ranges (AHR), maximum temperature of the warmest month (MTWM), minimum temperature of the coldest month (MTCM), and average elevation (ELE) of each transect. These data were assembled into a secondary environmental matrix and were prepared for canonical redundancy analysis (RDA). Detailed data are given in Additional file 1: Table S1.

\section{Data analysis \\ Spatial scale of species turnover}

We first compared both beetle and tree composition turnover at local and regional scales using the multisite dissimilarity method. A grouped plot-level similarity matrix was calculated and then partitioned into two different independent spatial components that reflected various $\beta$-diversity levels. It included turnover between sampling plots (total 15 plots) within three sub-regions and turnover between sampling plots among three subregions (total 45 plots). Considering all these turnover values produced by the multi-site dissimilarity method fall in the range from minimum zero to maximum one, beta regression method in Generalized linear models (GLMs) was performed to detect the relationships between both beetles and trees composition with variable of elevation gradient respectively. Then a Nonparametric Kruskal-Wallis ANOVA (analysis of variance) was further conducted to test for differences in Horn similarity values at various group and two spatial scales, followed by the appropriate post hoc tests. Data from the whole year of collections were combined for these analyses. The spatial component of turnover in tree species composition was investigated in an identical manner.

We also examined how $\beta$-null deviation values changed for meta-communities along the gradient from tropical to temperate for both tree and beetle community through beta regression method in Generalized linear models (GLMs) as mentioned above. The difference, in units of standard deviations, between the observed and mean expected raw turnover provided a measure of value that had sampling effects removed. The $\beta$-null deviation values based turnover estimates between tree and beetle assemblages are directly comparable to each other using a nonparametric Wilcoxon paired test, and any remaining correlation they had with gamma diversity (or other explanatory variables) could be interpreted as evidence for non-random ecological processes leading to intra-specific aggregation [79]. 


\section{Correlations of beetle turnover patterns}

A correlation (RDA) approach was used to test for association of tree and beetle species composition while controlling for spatial distance between sampling plots. First, we used forward and backward selection in an RDA assessing the influence of the abundance of individual tree species (Hellinger transformed) on beetle species composition to identify the most important tree species for inclusion in the ordination. This was necessary because there were more tree species than sampling units in our dataset. The selection procedure was conducted using the 'ordistep' function in 'vegan' package. RDA ('rda' in 'vegan') was then performed on beetle species composition (Hellinger transformed) with the selected tree species as constraining variables and spatial distance [converted to a rectangular matrix using PCNM [80], the 'pcnm' function in 'vegan'] as the conditioning variable (i.e., the effect which is removed). After that, variation partition was used to quantify the relative importance of spatial distance and trees abundance in determining the accompanying beetle species composition with an 'anova.cca' test in vegan. Similarly, to assess the impact of plant phylogenetic composition on beetle species composition, we first used phylogenetic principal components analysis ('phyl. pca' in 'phytools') to select the set of PC axes that explained $90 \%$ of variance in plant phylogenetic community composition. RDA was then performed on beetle species composition (Hellinger transformed) with selected PCNM converted spatial distance as the conditioning variable. $P$-values were assessed based on 999 random permutations. Because we wanted to explore the relationship between the dissimilarity of communities with environmental factors and spatial distance, we log-normalized the explanatory variables to make them comparable and then converted them to separated distance matrices. If both tree and beetle turnover occurred in response to climatic gradients or reflected bio-geographical influences (regional scale), we would not expect to find any positive association between beetle species composition and plant species/ phylogenetic turnover after accounting for the influence of geography (local scale).

\section{Coordination of beetles and trees}

To further compare the differences of relationship between beetles and trees with environmental variables at regional spatial scale, principal component analysis (PCA) was applied to the environmental variables, and the statistically significant components were selected by RDA. Beetle and tree species composition data were also Hellinger transformed. To quantify the homogeneity of dissimilarity variances within each transect, we compared the variances in the dissimilarity matrix using the 'betadisper' method [81]. This test is analogous to Levene's test for homogeneity of ANOVA variances.

\section{Supplementary Information}

The online version contains supplementary material available at https://doi. org/10.1186/s12983-022-00455-y.

Additional file 1. Table S1 showing the parameters of measured climatic variables of each FIT plot among three sample regions.

Additional file 2 . Appendix file 1 showing a name list of total of 64,710 bark beetles from 264 species were collected from all three regions.

Additional file 3. Appendix file 2 showing a name list of a total of 2184 tree individuals from 213 species from all three regions.

\section{Acknowledgements}

We thank Yun-Meng Wang, Hua-Yue Ma, Kun-Fu Chen, and Shan Sun from the Honghe University for the help in the laboratory and field; the specialists Andreas Weigel, from the Erfurt Natural History Museum, Germany; Dr. Heiko Gebhardt, from the University of Tübingen, Germany; and specialist Roger Beaver, now retired from the UK and currently in the Thailand helped to identify most of the bark beetle species. Two anonymous reviewers give many valuable revise suggestions and which significantly improved manuscript's quality. We are most grateful to all of them.

\section{Authors' contributions}

FL and LZM came up with the initial of the study, designed the work plan, carried out field collection works and performed data analysis, LZM interpreted data with the help of JW and YHL, FL and LZM wrote the manuscript. All authors have revised and approved the submitted version of the manuscript.

\section{Funding}

This study was supported by funds from the National Natural Science Foundation of China (Grant Nos. NSFC-31200322 \& 31760171), from Honghe University (grant nos. XJ16B05), and from the Second Integrated Scientific Surveys of Jinping Fenshuiling National Natural Reserve in China (2020-2024) from the Tropical Mountain Forest Eco-station in Southeast Yunnan (TFEY), Kunming, Institute of Botany of CAS.

\section{Availability of data and materials}

The dataset supporting the conclusions of this article are included within the article and its additional files.

\section{Declarations}

Ethics approval and consent to participate Not applicable.

Consent for publication

Not applicable.

\section{Competing interests}

The authors have no conflict of interest to declare.

\section{Author details}

${ }^{1}$ College of Biological and Agricultural Sciences, Honghe University, Mengzi 661199, Yunnan, China. ${ }^{2}$ Xishuangbanna Tropical Botanical Garden, Chinese Academy of Sciences, Mengla 666303, Yunnan, China.

Received: 24 August 2021 Accepted: 18 February 2022

Published online: 04 March 2022 


\section{References}

1. Novotny $\mathrm{V}$, Basset $Y$. Host specificity of insect herbivores in tropical forests. Proceedings of the Royal Society B: Biological Sciences. 2005;272:1083-90.

2. Vogel S, Bussler H, Finnberg S, Müller J, Stengel E, Thorn S: Diversity and conservation of saproxylic beetles in 42 European tree species: an experimental approach using early successional stages of branches. Insect Conserv Diversity 2020.

3. Hulcr J, Novotny $\bigvee$, Maurer BA, Cognato Al. Low beta diversity of ambrosia beetles (Coleoptera : Curculionidae: Scolytinae and Platypodinae) in lowland rainforests of Papua New Guinea. Oikos. 2008;117:214-22.

4. Novotny V, Miller SE, Hulcr J, Drew RAI, Basset Y, Janda M, Setliff GP, Darrow K, Stewart AJA, Auga J, et al. Low beta diversity of herbivorous insects in tropical forests. Nature. 2007;448:692-U698.

5. Ødegaard F, Diserud OH, Østbye K. The importance of plant relatedness for host utilization among phytophagous insects. Ecol Lett. 2005:8:612-7.

6. Novotny V, Basset Y, Miller SE, Weiblen GD, Bremer B, Cizek L, Drozd P. Low host specificity of herbivorous insects in a tropical forest. Nature. 2002;416:841-4

7. Basset Y, Samuelson GA, Allison A, Miller SE. How many species of host-specific insects feed on a species of tropical tree? Biol J Lin Soc 1996;59:201-16.

8. Erwin TL. Tropical forests: their richness in Coleoptera and other arthropod species. Coleopt Bull. 1982;36:2.

9. Bruno JF, Stachowicz JJ, Bertness MD. Inclusion of facilitation into ecological theory. Trends Ecol Evol. 2003;18:119-25.

10. Hutchinson GE. Concluding remarks. Cold Spring Harb Symp Quant Biol. 1957;22:13

11. Rahbek C. The role of spatial scale and the perception of large-scale species-richness patterns. Ecol Lett. 2005;8:224-39.

12. McGill BJ. Matters of Scale. Science. 2010;328:575-6.

13. Whittaker RH. Evolution and measurement of species diversity. Taxon. 1972;21:213-51.

14. Kemp JE, Linder HP, Ellis AG. Beta diversity of herbivorous insects is coupled to high species and phylogenetic turnover of plant communities across short spatial scales in the Cape Floristic Region. J Biogeogr. 2017:44:1813-23

15. Batstone RT, Carscadden KA, Afkhami ME, Frederickson ME. Using niche breadth theory to explain generalization in mutualisms. Ecology. 2018:99:1039-50

16. Afkhami ME, McIntyre PJ, Strauss SY. Mutualist-mediated effects on species' range limits across large geographic scales. Ecol Lett. 2014; 17:1265-73.

17. Qian H, Chen S, Mao L, Ouyang Z. Drivers of $\beta$-diversity along latitudinal gradients revisited. Glob Ecol Biogeogr. 2013;22:659-70.

18. Qian H, Ricklefs RE. A latitudinal gradient in large-scale beta diversity for vascular plants in North America. Ecol Lett. 2007:10:737-44.

19. Patricia K, Lennon JJ, Gaston KJ. Are there latitudinal gradients in species turnover? Glob Ecol Biogeogr. 2003;12:483-98.

20. Soininen J, McDonald R, Hillebrand $H$. The distance decay of similarity in ecological communities. Ecography. 2007:30:3-12.

21. Soininen J, Lennon JJ, Hillebrand $\mathrm{H}$. A multivariate analysis of beta diversity across organisms and environments. Ecology. 2007:88:2830-8.

22. Baselga A. Partitioning the turnover and nestedness components of beta diversity. Glob Ecol Biogeogr. 2010;19:134-43.

23. Soininen J, Heino J, Wang J. A meta-analysis of nestedness and turnover components of beta diversity across organisms and ecosystems. Glob Ecol Biogeogr. 2018;27:96-109.

24. Kraft NJB, Valencia R, Ackerly DD. Functional traits and niche-based tree community assembly in an Amazonian Forest. Science. 2008;322:580-2.

25. Chase JM. Stochastic community assembly causes higher biodiversity in more productive environments. Science. 2010;328:1388-91.

26. Aukema JE. Distribution and dispersal of desert mistletoe is scaledependent, hierarchically nested. Ecography. 2004:27:137-44.

27. Whittaker RJ, Willis KJ, Field R. Scale and species richness: towards a general, hierarchical theory of species diversity. J Biogeogr. 2001;28:453-70.

28. Pearson RG, Dawson TP. Predicting the impacts of climate change on the distribution of species: are bioclimate envelope models useful? Glob Ecol Biogeogr. 2003;12:361-71.
29. Pellissier L, Fiedler K, Ndribe C Dubuis A, Pradervand J-N Guisan A Rasmann S. Shifts in species richness, herbivore specialization, and plant resistance along elevation gradients. Ecol Evol. 2012;2:1818-25.

30. Hoiss B, Krauss J, Potts SG, Roberts S, Steffan-Dewenter I. Altitude acts as an environmental filter on phylogenetic composition, traits and diversity in bee communities. Proc R Soc B: Biol Sci. 2012;279:4447-56.

31. Schaffers AP, Raemakers IP, Sýkora KV, ter Braak CJF. Arthropod assemblages are best predicted by plant species composition. Ecology. 2008;89:782-94.

32. Siemann E, Tilman D, Haarstad J, Ritchie M. Experimental tests of the dependence of Arthropod diversity on plant diversity. Am Nat. 1998;152:738-50

33. Pellissier L, Ndiribe C, Dubuis A, Pradervand J-N, Salamin N, Guisan A, Rasmann S. Turnover of plant lineages shapes herbivore phylogenetic beta diversity along ecological gradients. Ecol Lett. 2013;16:600-8.

34. Whitfeld TJS, Novotny V, Miller SE, Hrcek J, Klimes P, Weiblen GD. Predicting tropical insect herbivore abundance from host plant traits and phylogeny. Ecology. 2012;93:S211-22.

35. Hawkins BA, Porter EE. Does herbivore diversity depend on plant diversity? The case of California Butterflies. Am Nat. 2003;161:40-9.

36. Burkle LA, Myers JA, Belote RT. The beta-diversity of species interactions: Untangling the drivers of geographic variation in plant-pollinator diversity and function across scales. Am J Bot. 2016;103:118-28.

37. Hulcr J, Mogia M, Isua B, Novotny V. Host specificity of ambrosia and bark beetles (Col., Curculionidae: Scolytinae and Platypodinae) in a New Guinea rainforest. Ecol Entomol. 2007:32:762-72.

38. Wu J, Yu X-D, Zhou H-Z. The saproxylic beetle assemblage associated with different host trees in Southwest China. Insect Science. 2008;15:251-61.

39. Wende B, Gossner MM, Grass I, Arnstadt T, Hofrichter M, Floren A, Linsenmair KE, Weisser WW, Steffan-Dewenter I. Trophic level, successional age and trait matching determine specialization of deadwoodbased interaction networks of saproxylic beetles. Proc R Soc B: Biol Sci. 2017;284:20170198.

40. Farrell BD, Sequeira AS, O'Meara BC, Normark BB, Chung JH, Jordal BH. The evolution of agriculture in beetles (Curculionidae: Scolytinae and Platypodinae). Evolution. 2001;55:2011-27.

41. Beaver RA, et al. Insect-fungus relationship in the bark and Ambrosia beetles. In: Wilding N, et al., editors. Insect-fungus interactions. London: Academic Press; 1989

42. Beaver RA. Host specificity of temperate and tropical animals. Nature. 1979:281:139-41.

43. Sobek S, Steffan-Dewenter I, Scherber C, Tscharntke T. Spatiotemporal changes of beetle communities across a tree diversity gradient. Divers Distrib. 2009;15:660-70

44. Hulcr J, Beaver RA, Puranasakul W, Dole SA, Sonthichai S. A comparison of bark and ambrosia beetle communities in two forest types in Northern Thailand (Coleoptera: Curculionidae: Scolytinae and Platypodinae). Environ Entomol. 2008:37(1461-1470):1410.

45. Leal CRO, Oliveira Silva J, Sousa-Souto L, de Siqueira NF. Vegetation structure determines insect herbivore diversity in seasonally dry tropical forests. J Insect Conserv. 2016;20:979-88.

46. Dyer LA, Singer MS, Lill JT, Stireman JO, Gentry GL, Marquis RJ, Ricklefs RE, Greeney HF, Wagner DL, Morais HC, et al. Host specificity of Lepidoptera in tropical and temperate forests. Nature. 2007:448:696-9.

47. Ødegaard F. How many species of arthropods? Erwin's estimate revised. Biol J Lin Soc. 2008;71:583-97.

48. Stork NE. How many species are there? Biodivers Conserv. 1993;2:215-32.

49. Gaston KJ, Genney DR, Thurlow M, Hartley SE. The geographical range structure of the holly leaf-miner. IV. Effects of variation in host-plant quality. J Anim Ecol. 2004;73:911-24

50. Forbes AA, Devine SN, Hippee AC, Tvedte ES, Ward AKG, Widmayer HA, Wilson CJ. Revisiting the particular role of host shifts in initiating insect speciation. Evolution. 2017:71:1126-37.

51. Soberón J, Nakamura M. Niches and distributional areas: concepts, methods, and assumptions. Proc Natl Acad Sci. 2009:106:19644-50.

52. Harrison S, Ross SJ, Lawton JH. Beta diversity on geographic gradients in Britain. J Anim Ecol. 1992;61:151-8. 
53. Berg MP, Kiers ET, Driessen G, Van Der Heijden M, Kooi BW, Kuenen F, Liefting $M$, Verhoef HA, Ellers J. Adapt or disperse: understanding species persistence in a changing world. Glob Change Biol. 2010;16:587-98.

54. Thompson PL, Fronhofer EA. The conflict between adaptation and dispersal for maintaining biodiversity in changing environments. Proc Natl Acad Sci. 2019;116:21061-7.

55. Bennett JR, Gilbert B. Contrasting beta diversity among regions: how do classical and multivariate approaches compare? Glob Ecol Biogeogr. 2016;25:368-77.

56. Engel T, Blowes S, McGlinn D, May F, Gotelli N, McGill B, Chase J. Resolving the species pool dependence of beta-diversity using coverage-based rarefaction. 2020

57. Castro FSd, Da Silva PG, Solar R, Fernandes GW, Neves FdS: Environmental drivers of taxonomic and functional diversity of ant communities in a tropical mountain. Insect Conserv Divers. 2020;13, 393.

58. Kuchenbecker J, Macedo-Reis LE, Fagundes M, Neves FS. Spatiotemporal distribution of herbivorous insects along always-green mountaintop forest islands. Front For Glob Change 2021;4.

59. Ranger CM, Biedermann PHW, Phuntumart V, Beligala GU, Ghosh S, Palmquist DE, Mueller R, Barnett J, Schultz PB, Reding ME, Benz JP. Symbiont selection via alcohol benefits fungus farming by ambrosia beetles. Proc Natl Acad Sci. 2018;115:4447-52.

60. Myers N, Mittermeier RA, Mittermeier CG, da Fonseca GAB, Kent J. Biodiversity hotspots for conservation priorities. Nature. 2000;403:853.

61. Kreft H, JetzW. Global patterns and determinants of vascular plant diversity. Proc Natl Acad Sci. 2007;104:5925-30.

62. Barthlott W, Lauer W, Placke A. Global distribution of species diversity in vascular plants: Towards a world map of phytodiversity. Erdkunde. 1996;50:317-27.

63. Guoyu Lan YH, Cao M, Zhu H, Wang H, Zhou S, Deng X, Cui J, Huang J, Liu L, Xu H, Song J, He Y. Establishment of Xishuangbanna tropical forest dynamics plot: species compositions and spatial distribution patterns. Chin J Plant Ecol. 2008;32:287-98.

64. Wen H-D. Lin L-X, J Yang, Y-H Hu, M Cao, Y-H Liu, Z-Y Lu, Y-N Xie: Species composition and community structure of a $20 \mathrm{hm} 2$ plot of mid-mountain moist evergreen broad-leaved forest on the Mts. Ailaoshan, Yunnan Province China. Chin J Plan Ecolo. 2018;42:419-29.

65. Huang H, Chen Z, Liu D, He G, He R, Li D, Xu K. Species composition and community structure of the Yulongxueshan (Jade Dragon Snow Mountains) forest dynamics plot in the cold tem- perate spruce-fir forest, Southwest China. Biodivers Sci. 2017;25:10.

66. Charney NRS: Vegetarian: Jost Diversity Measures for Community Data. R package version $12 \mathrm{https}$ //www.CRANR-projectorg/package=vegetarian 2012.

67. Jost L. Partitioning diversity into independent alpha and beta components. Ecology. 2007;88:2427-39.

68. Tuomisto H. A diversity of beta diversities: straightening up a concept gone awry. Part 1. Defining beta diversity as a function of alpha and gamma diversity. Ecography. 2010;33:2-22.

69. Myers JA, Chase JM, Jiménez I, Jørgensen PM, Araujo-Murakami A, Paniagua-Zambrana N, Seidel R. Beta-diversity in temperate and tropical forests reflects dissimilar mechanisms of community assembly. Ecol Lett. 2013;16:151-7.

70. Kraft NJB, Comita LS, Chase JM, Sanders NJ, Swenson NG, Crist TO, Stegen JC, Vellend M, Boyle B, Anderson MJ, et al. Disentangling the drivers of $\beta$ diversity along latitudinal and elevational gradients. Science. 2011;333:1755-8.

71. Crist TO, Veech JA, Gering JC, Summerville KS. Partitioning species diversity across landscapes and regions: a hierarchical analysis of alpha, beta, and gamma diversity. Am Nat. 2003;162:734-43.

72. Stegen JC, Freestone AL, Crist TO, Anderson MJ, Chase JM, Comita LS, Cornell HV, Davies KF, Harrison SP, Hurlbert AH, et al. Stochastic and deterministic drivers of spatial and temporal turnover in breeding bird communities. Glob Ecol Biogeogr. 2013;22:202-12.

73. Tucker CM, Shoemaker LG, Davies KF, Nemergut DR, Melbourne BA. Differentiating between niche and neutral assembly in metacommunities using null models of $\beta$-diversity. Oikos. 2016;125:778-89.

74. Zhang J-L. Plantlist: looking up the status of plant scientific names based on the plant list database (version 0.3.7). 2018.

75. Webb CO, Donoghue MJ. Phylomatic: tree assembly for applied phylogenetics. Mol Ecol Notes. 2005;5:181-3.
76. Davies TJ, Barraclough TG, Chase MW, Soltis PS, Soltis DE, Savolainen V. Darwin's abominable mystery: Insights from a supertree of the angiosperms. Proc Natl Acad Sci. 2004;101:1904-9.

77. Bryant JA, Lamanna C, Morlon H, Kerkhoff AJ, Enquist BJ, Green JL. Microbes on mountainsides: contrasting elevational patterns of bacterial and plant diversity. Proc Natl Acad Sci. 2008;105:11505-11.

78. Kembel SW, Cowan PD, Helmus WK, Cornwell WK, Morlon H, Ackerly DD, Blomberg SP, Webb CO. Picante: R tools for integrating phylogenies and ecology. Bioinformatics. 2010;26:1463.

79. Ulrich W, Gotelli NJ. Null model analysis of species associations using abundance data. Ecology. 2010;91:3384-97.

80. Dray S, Legendre P, Peres-Neto PR. Spatial modelling: a comprehensive framework for principal coordinate analysis of neighbour matrices (PCNM). Ecol Model. 2006;196:483-93.

81. Anderson MJ, Ellingsen KE, McArdle BH. Multivariate dispersion as a measure of beta diversity. Ecol Lett. 2006;9:683-93.

\section{Publisher's Note}

Springer Nature remains neutral with regard to jurisdictional claims in published maps and institutional affiliations.

Ready to submit your research? Choose BMC and benefit from:

- fast, convenient online submission

- thorough peer review by experienced researchers in your field

- rapid publication on acceptance

- support for research data, including large and complex data types

- gold Open Access which fosters wider collaboration and increased citations

- maximum visibility for your research: over $100 \mathrm{M}$ website views per year

At BMC, research is always in progress.

Learn more biomedcentral.com/submissions 